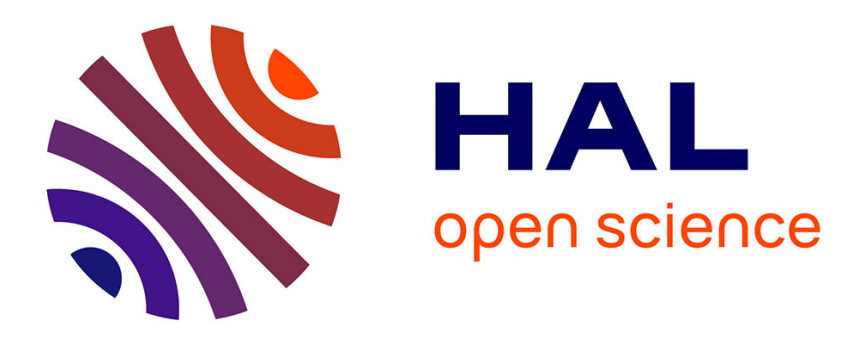

\title{
The two types of El-Niño and their impacts on the length of day
}

O de Viron, Jean O. Dickey

\section{To cite this version:}

O de Viron, Jean O. Dickey. The two types of El-Niño and their impacts on the length of day. Geophysical Research Letters, 2014, 41, pp.3407 - 3412. 10.1002/2014GL059948 . hal-01087222

\section{HAL Id: hal-01087222 \\ https://hal.science/hal-01087222}

Submitted on 26 Nov 2014

HAL is a multi-disciplinary open access archive for the deposit and dissemination of scientific research documents, whether they are published or not. The documents may come from teaching and research institutions in France or abroad, or from public or private research centers.
L'archive ouverte pluridisciplinaire HAL, est destinée au dépôt et à la diffusion de documents scientifiques de niveau recherche, publiés ou non, émanant des établissements d'enseignement et de recherche français ou étrangers, des laboratoires publics ou privés. 


\title{
1 The two types of El-Nino and their impacts on the Length-of-day
}

\author{
O. de Viron and J. O. Dickey
}

At the interannual to decadal timescale, the changes ins the Earth rotation rate are linked with the El-Niño South46 ern Oscillation phenomena through changes in the $\mathrm{Atmo}^{47}$ spheric Angular Momentum. As climatic studies demon ${ }^{48}$ strate that there were two types of El-Niño events, namely Eastern Pacific (EP) and Central Pacific (CP) events, we investigate how each of them affect the Atmospheric Angular Momentum. We show in particular that EP events are $\operatorname{asso}_{\overline{53}}$ ciated with stronger variations of the Atmospheric Angulas 4 Momentum and length-of-day. We explain this differences by the stronger pressure gradient over the major mountairs 6 ranges, due to a stronger and more efficiently localized pres ${ }^{57}$ sure dipole over the Pacific Ocean in the case of EP events.5.

\section{Introduction}

The Earth rotation is not constant in time; in particular ${ }_{64}$ the Earth rotation rate, and the associated length-of-day $5_{5}$ (LOD) show fluctuations in a broad band of periods. $A_{6}$ global description of the causes at the different time scales, can be found in Hide and Dickey [1991]. The main cause of LOD change for periods ranging from a few days to a few years is the Earth atmosphere interaction. As soon as in terannual fluctuations were observed in the Earth rotation data, the El-Niño Southern Oscillation (ENSO) was shown to play a major role [Chao, 1984, 1988], as a warm - El-Niño - event has been shown associated with a longer day and a cold - La Niña - event associated with a shorter day.

Classical El-Niño events are characterized by maximum $m^{75}$ warm water anomaly in the Eastern Pacific Ocean, and referred as the Eastern Pacific (EP) El-Niño events, with Sea Surface Temperature (SST) anomalies in the Nino-3 region ${ }^{78}$ $\left(5^{\circ} \mathrm{S}-5^{\circ} \mathrm{N}, 150^{\circ} \mathrm{W}\right.$ to $\left.90^{\circ} \mathrm{W}\right)$. Frequent occurrences of $\mathrm{a}^{79}$ new type of El Niño have been observed since the 1990s, with the maximum warm SST anomaly in the Central Equatoria1 Pacific [e.g. Latif et al., 1997], the Nino-4 region $\left(5^{\circ} \mathrm{S}-5^{82}\right.$ $\mathrm{N}, 160^{\circ} \mathrm{E}$ to $\left.150^{\circ} \mathrm{W}\right)$. These are known with a variety o1 names, Central Pacific (CP) El Niño [Kao and $Y u, 2009 ; Y^{84}$ and Kim, 2010], warm pool El Niño [Kug et al., 2009], date $e^{85}$ line El Niño [Larkin and Harrison, 2005] or El Niño Modok ${ }^{6}$ [Ashok et al., 2007]. These two ENSO types have differ ${ }^{87}$ ent teleconnection patterns and climatic consequences [e.g.8. Weng et al., 2009; Kim et al., 2009; Ashok and Yamagata, 2009; Kim et al., 2009]. In this study, we investigate hove the EP and CP event mechanisms affect the Earth rotation ${ }^{1}$ differently.

\footnotetext{
${ }^{1}$ Université Paris Diderot, Sorbonne Paris Cité, and Institut de Physique du Globe de Paris (UMR7159), now at Univ La Rochelle, CNRS, UMR 7266, Littoral Environnement \& Société LIENSs, F-17000 La Rochelle, France

${ }^{2}$ Jet Propulsion Laboratory, California Institute of Technology, Pasadena, CA

Copyright 2014 by the American Geophysical Union. $0094-8276 / 14 / \$ 5.00$
}

Classically, the atmospheric impact on the Earth rotation is estimated using the angular momentum (AM) approach: the solid Earth+atmosphere system is considered as isolated, the atmospheric angular momentum (AAM) is computed, considering that any variation of this quantity is compensated by an opposite variation of the Earth AM. The AAM is composed of two parts, a mass term corresponding to the AM associated with the rigid rotation of the atmosphere with the solid Earth, and a motion term corresponding to the relative AM of the atmosphere with respect to the solid Earth.

Alternatively, as first proposed by Widger [1949], one can also consider the atmosphere as an external forcing to the solid Earth. The total atmospheric torque acting on the solid Earth is the sum of four effects: a pressure effect on the topography, the gravitational interaction between the atmospheric and the Earth masses, the wind friction drag over the Earth surface, and the interaction between the gravity wave and the topography [Barnes et al., 1983; Huang et al., 1999]. The last term is generally negligible [de Viron and Dehant, 2003]. The topography from the atmospheric Global Circulation Models (GCMs) is classically defined with respect to the geoid; consequently, the topographic torque computed using such a topography is actually the sum of topography and gravitational torque, and is known as the mountain torque. The total torque is thus computed as the sum of the mountain and the friction torque.

Generally, the mountain torque generates the axial AAM variations, which are eventually damped away by the friction torque [de Viron et al., 2001; Lott et al., 2008; Marcus et al., 2011]. A noticeable exception is the seasonal AAM anomaly, which is generated by an anomalous friction torque over the Indian Ocean [de Viron et al., 2002]. Both the atmospheric $\mathrm{AM}$ (AAM) and torques can be estimated from the output, whereas the inherent accuracy limits this method at the understanding of the physical processes but does not allow to estimate Earth rotation variation with a precision allowing to use it in the frame of geodetic studies [de Viron and Dehant, 2003].

The torque approach was used for understanding the atmospheric angular momentum anomaly associated with the ENSO phenomenon [Wolf and Smith, 1987; Ponte and Rosen, 1999; de Viron et al., 2001; Marcus et al., 2010]. During the ENSO event, a low pressure appears in the Eastern part of the Pacific Ocean, which creates a positive torque over the atmosphere and consequently increases the AAM and the LOD. The increased surface wind over the Northern Pacific increases the friction torque, which eventually cancels the AAM anomaly.

\section{Data Preparation}

In this study, we used outputs of the National Centers for Environmental Prediction - National Center for Atmospheric Research (NCEP-NCAR) reanalysis [Kalnay et al., 1996], from 1948 to 2013. Data includes the zonal wind field (as a function of time, pressure level, latitude, and longitude), the surface pressure and East-West wind stress (as a function of time, latitude, and longitude), and the model orography. 


$$
\begin{aligned}
& H_{Z}^{\text {motion }}=\frac{a^{3}}{g} \int_{0}^{2 \pi} \int_{0}^{\pi} \int_{0}^{P_{\text {surface }}} u(p, \theta, \lambda) \sin ^{2} \theta d p d \theta d \lambda{ }_{124}^{123} \\
& H_{Z}^{\text {mass }}=\frac{a^{4} \Omega}{g} \int_{0}^{2 \pi} \int_{0}^{\pi} P_{\text {surface }}(\theta, \lambda) \sin ^{3} \theta d \theta d \lambda,
\end{aligned}
$$

$$
\Gamma_{Z}^{\text {Mountain }}=a^{3} \int_{0}^{2 \pi} \int_{0}^{\pi} \frac{\partial P_{\text {surface }}(\theta, \lambda)}{\partial \lambda} h(\theta, \lambda) \sin \theta d \theta d \lambda_{141}^{140}
$$

$$
\Gamma_{Z}^{\text {Friction }}=-a^{3} \int_{0}^{2 \pi} \int_{0}^{\pi} \tau_{\lambda} \sin ^{2} \theta d \theta d \lambda
$$

where $h$ is the orography and $\tau_{\lambda}$ is the zonal friction drag. The longitude derivative of the surface pressure is estimated using a using a five-point stencil [e.g. Burden and Faire\$44 2010]:

$$
\left.\frac{d f(x)}{d x}\right|_{i} \simeq \frac{8 f_{i-2}-f_{i-1}+f_{i+1}-8 f_{i+2}}{12 \Delta x}
$$

The EP and CP Niño index are estimated, following Renso and Jin [2011], from the Niño 3 and Niño 4 index from the NOAA Climate Prediction Center, made available at the Earth System Research Laboratory website. Defining

$$
\alpha=\left\{\begin{array}{l}
\frac{2}{5} \\
0
\end{array} \text { where } \mathrm{Nino}_{3} \cdot \mathrm{Nino}_{4}<0\right.
$$

$N_{E P}=\mathrm{NinO}_{3}-\alpha \cdot \mathrm{NinO}_{4}$

$N_{C P}=\mathrm{NinO}_{4}-\alpha \cdot \mathrm{NinO}_{3}$

$$
\begin{aligned}
& t_{X}^{+}=\left\{t: N_{X}(t)>\sigma_{N_{X}}\right\} \\
& t_{X}^{0}=\left\{t:-\sigma_{N_{X}} \leq N_{X}(t) \leq \sigma_{N_{X}}\right\} \\
& t_{X}^{-}=\left\{t: N_{X}(t)<-\sigma_{N_{X}}\right\}
\end{aligned}
$$

We then compute a composite anomaly by making the dif- $\mathbf{f}^{74}$ ference between the average positive state and the averagi $e^{5}$ negative state.

$$
C_{X}(x, y)=\overline{C\left(t_{X}^{+}, x, y\right)}-\overline{C\left(t_{X}^{-}, x, y\right)}
$$

\section{ENSO induced AAM anomaly}

We estimated the composite impact of the ENSO by computing the mean AAM for $t_{E P}^{+, 0,-}$ and $t_{C P}^{+, 0,-}$. Whisker diagrams for each of them are plotted on Figure 1, the associated AAM anomaly can be observed on the left axis, whereas the corresponding LOD anomaly can be read on the right axis. The above average values of both EP and $\mathrm{CP}$ indices are seen to be associated with anomalously high value of AAM, whereas below average index values are associated with anomalously low value of AAM. The difference is found significant at more than $99 \%$ with an ANOVA test (see Davis [1986], for example). The $t_{X}^{0}$ are the largest set, with about 500 epochs, whereas the + and - have about 100 . Due to the one-year smoothing, the epochs from the same winter are not independents; consequently, for the statistics, only the mean value over a given winter was kept. The ANOVA group size was subsequently of the order of 15 to 20 winters for the + and - epochs, and about 100 for the 0 epochs.

The EP anomaly is stronger: in particular, the difference of mean between above average and below average is nearly 2.5 time larger for EP than for CP.

\section{AAM and torque for the two types of ENSO events}

Such a difference in AAM signature finds its explanation in the torque acting on the atmosphere from the solid Earth. As explained in Ponte and Rosen [1999], the torque causing the AAM anomaly in the case of an ENSO event is the mountain torque associated with the pressure anomaly. The Southern Oscillation is known (see for instance Clarke [2008]) to be associated with a pressure East-West dipole over the Pacific. However, depending on the type of events, the location of this dipole is directly linked to that of the SST anomaly, as shown on Figure 2. In particular, the EP negative pole is centred on the east coast of the Pacific Ocean, whereas the WP negative pole is centred on the middle of the Pacific Ocean.

The mountain torque is generated by a longitude difference of pressure acting over a mountain range: if the pressure over the West slope of the mountain is stronger than that over the East side, it acts to push the Earth to rotate faster and slows the atmosphere rotation down. Consequently, to understand the impact of the ENSO events on the AAM, mostly the pressure over the main mountain ranges, Himalayas, Andes, and Rocky Mountains are relevant.

The Figure 3 focus over those three mountain ranges, showing the topography in a gray scale, and the pressure anomaly with color contours. The most obvious difference occurs over Himalayas: in case of the EP ENSO, there is a strong pressure gradient with the pressure on the West slope being smaller, whereas there is no such gradient in case of CP ENSO. Over the Andes, a pressure gradient exists in both cases, but it is shifted East in the case of CP ENSO, and is consequently not acting over topography, while the gradient in case of EP ENSO closely follows the coast, and the mountain range, and is consequently very efficient. Over the Rocky Mountains, a pressure gradient on the West slope can be noted in both cases, but the more westward location of the pressure dipole for the $\mathrm{CP}$ events makes it weaker. Consequently, the mountain torque associated with the EP ENSO is stronger in all the three cases. The values of the 
mountain torque, total and integrated over each continents45 are given on Table 1 . The table shows that there is als some effect over the topography of Africa.

The friction torque shows similar features in case of C $\mathrm{C}^{48}$ and EP ENSO, but they are stronger in the case of the EF9 ENSO. The anomaly maps are shown on Figure 4. The total friction torque is at the level of 10 Hadleys for EP ENSO $0^{51}$ and about a third for CP ENSO, with maximum effect over the Pacific and over the part of the Antarctic Ocean, Nort $5_{554}^{253}$ of the Indian Ocean, as seen on Table 2. The stronger fric $\bar{c}_{\overline{5} 5}$ tion in the case of EP ENSO is logical, considering that thes6 wind anomaly is stronger in the CP ENSO case. A stronger 7 friction torque is also necessary to break down the largess AAM anomaly resulting from the larger mountain torque iaq9 the EP ENSO case.

\section{Conclusions}

In this paper, we investigate the impact of the ENSO ${ }^{264}$ the Earth rotation, and show that the AAM signature of theo Eastern Pacific type of ENSO is more than twice as larger than that of the Central Pacific ENSO. We then explain this 88 difference using the torque approach, as it allows us to de $\mathrm{e}^{69}$ termine where and how the AM is exchanged between the $2^{\circ}$ solid Earth and the atmosphere. As expected, we also fin ${ }^{2 \bar{d}^{1}}$ stronger torques for the EP ENSO, for both the mountain and the friction torque. The ratio of the dominant mountain torque created by the Eastern Pacific events to that created by the Central Pacific events varies between 1.5 and 3.96 with the ratio on the total mountain torque being 2.6. Theq strongest contributing continents are Asia, North and Southa America and Africa. For the frictional torque, this ratio isg 3.0. Looking at the associated surface pressure anomal we show that the pressure dipole for EP ENSO is posłân tioned so that there is a strong East-West pressure gradieni ${ }^{2}$ over the major mountain ranges: Himalayas, Andes, Rock $y^{23}$ Mountains, whereas the pressure dipole for CP ENSO ${ }_{11}^{284}$ not as efficiently positioned. The stronger mountain torque ${ }_{286}^{285}$ explains the stronger AAM anomaly. The stronger wind as sociated with the anomaly generate a stronger negative fric $\varepsilon_{\overline{8}}$ tion torque at the Earth surface, which cancels the AAMg anomaly.

This case study demonstrates how the torque approacda provides additional insights, explaining the AAM changeg92 In this case, it allows to provide an explanation as why thes two types of ENSO events do not have the same impact o14 $^{4}$ the Earth rotation.

Acknowledgments. We gratefully acknowledge discussions7 with Tong Lee regarding the two ENSO type literatures. Thiss study was supported by the CNES through the TOSCA prograngg and by the Institut Universitaire de France (OdV). The work ofo JOD is a phase of research carried out at the Jet Propulsiosar Laboratory, California Institute of Technology, sponsored by the2 National Aeronautics and Space Administration (NASA). It is 303 pleasure to thank the editor (Eric Calais) and two anonymouss reviewers for their help in improving the paper.

\section{References}

Ashok, K., and T. Yamagata (2009), Climate Change The 13.11 Nino with a difference, Nature, 461(7263), 481-484, doir2 10.1038/461481a.

Ashok, K., S. K. Behera, S. A. Rao, H. Weng, and T. Yamagatza4 (2007), El Nino Modoki and its possible teleconnection, J. o1: Geophys. Res.-Ocean, 112(C11), doi:10.1029/2006JC003798316 Barnes, R., R. Hide, A. White, and C. Wilson (1983), Atmot7 spheric angular momentum fluctuations, length-of-day changess and polar motion, Proceedings of the Royal Society of Londopis A. Mathematical and Physical Sciences, 387(1792), 31-73. 320
Burden, R., and J. Faires (2010), Numerical Analysis, Cengage Learning.

Chao, B. (1984), Interannual length-of-day variation with relation to the Southern Oscillation/El-Nino, Geophys. Res. Let., 11 (5), 541-544, doi:10.1029/GL011i005p00541.

Chao, B. F. (1988), Correlation of Interannual Length-of-Day Variation With El-Niño/Southern Oscillation, 1972-1986, Jo. of Geophys. Res., 93(B7), 7709-7715.

Clarke, A. (2008), An Introduction to the Dynamics of El Nino \&5 the Southern Oscillation, Elsevier Science.

Davis, J. (1986), Statistics and Data Analysis in Geology, John Wiley \& Sons.

de Viron, O., and V. Dehant (2003), Tests on the validity of atmospheric torques on earth computed from atmospheric model outputs, J. of Geophys. Res., 108(B2), 2068.

de Viron, O., S. Marcus, and J. Dickey (2001), Atmospheric torques during the winter of 1989: Impact of ENSO and NAO positive phases, Geophys. Res. Lett, 28(10), 1985-1988.

de Viron, O., J. O. Dickey, and S. L. Marcus (2002), Annual atmospheric torques: Processes and regional contributions, Geophys. Res. Let., 29(7), 44-1-44-3, doi:10.1029/2001GL013859.

de Viron, O., S. Marcus, and J. Dickey (2001), Atmospheric torques during the winter of 1989: Impact of ENSO and NAO positive phases, Geophys. Res. Let., 28(10), 1985-1988.

Hide, R., and J. O. Dickey (1991), Earth's variable rotation, Science, 253, 629-637.

Huang, H., P. Sardeshmukh, and K. Weickmann (1999), The balance of global angular momentum in a long-term atmospheric data set, Journal of Geophysical Research: Atmospheres, 104(D2), 2031-2040, doi:10.1029/1998JD200068.

Kalnay, E., M. Kanamitsu, R. Kistler, W. Collins, D. Deaven, L. Gandin, M. Iredell, S. Saha, G. White, J. Woollen, Y. Zhu, M. Chelliah, W. Ebisuzaki, W. Higgins, J. Janowiak, K. Mo, C. Ropelewski, J. Wang, A. Leetmaa, R. Reynolds, R. Jenne, and D. Joseph (1996), The NCEP/NCAR 40-year reanalysis project, Bull. Am. Met. Soc., 77(3), 437-471, doi: 10.1175/1520-0477(1996)077.

Kao, H.-Y., and J.-Y. Yu (2009), Contrasting Eastern-Pacific and Central-Pacific Types of ENSO, J. of Clim., 22(3), 615-632, doi:10.1175/2008JCLI2309.1.

Kim, H.-M., P. J. Webster, and J. A. Curry (2009), Impact of Shifting Patterns of Pacific Ocean Warming on North Atlantic Tropical Cyclones, Science, 325(5936), 77-80, doi: 10.1126/science.1174062.

Kug, J.-S., F.-F. Jin, and S.-I. An (2009), Two Types of El Nino Events: Cold Tongue El Nino and Warm Pool El Nino, J. Clim., 22(6), 1499-1515, doi:10.1175/2008JCLI2624.1.

Larkin, N., and D. Harrison (2005), Global seasonal temperature and precipitation anomalies during El Nino autumn and winter, Geophys. Res. Let., 32(16), doi:10.1029/2005GL022860.

Latif, M., R. Kleeman, and C. Eckert (1997), Greenhouse warming, decadal variability, or El Nino? An attempt to understand the anomalous 1990s, J. of Clim., 10(9), 2221-2239, doi:10.1175/1520-0442(1997) 010<2221:GWDVOE > 2.0.CO;2.

Lott, F., O. De Viron, P. Viterbo, and F. Vial (2008), Axial atmospheric angular momentum budget at diurnal and subdiurnal periodicities, J. Atm. Sc., 65(1), 156-171.

Marcus, S. L., O. de Viron, and J. O. Dickey (2010), Interannual atmospheric torque and El Niño-Southern Oscillation: Where is the polar motion signal?, J. of Geophys. Res., 115(B12), B12,409.

Marcus, S. L., O. de Viron, and J. O. Dickey (2011), Abrupt atmospheric torque changes and their role in the 1976-1977 climate regime shift, J. of Geophys. Res.-Atmosphere, 116, doi:10.1029/2010JD015032.

Ponte, R. M., and R. D. Rosen (1999), Torques responsible for evolution of atmospheric angular momentum during the 198283 El Niño, J. of the Atm. Sci., 56(19), 3457-3462.

Ren, H.-L., and F.-F. Jin (2011), Nino indices for two types of ENSO, Geophys. Res. Let., 38, doi:10.1029/2010GL046031.

Weng, H., S. K. Behera, and T. Yamagata (2009), Anomalous winter climate conditions in the Pacific rim during recent El Niño Modoki and El Niño events, Clim. Dyn., 32(5), 663-674, doi:10.1007/s00382-008-0394-6.

Widger, W. K. (1949), A study of the flow of angular momentum in the atmosphere, J. Meteor, 6, 292299. 


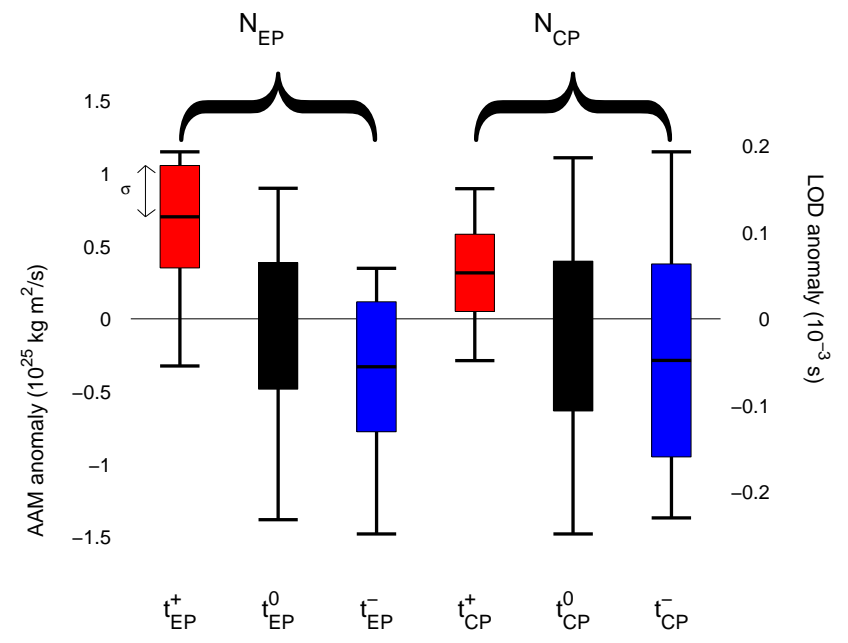

Figure 1. Whisker diagram of the AAM during times where indices $\left(N_{E P}\right.$ on the left, $N_{C P}$ on the right) are 1$\sigma$ above average, below average, or at the neutral state.

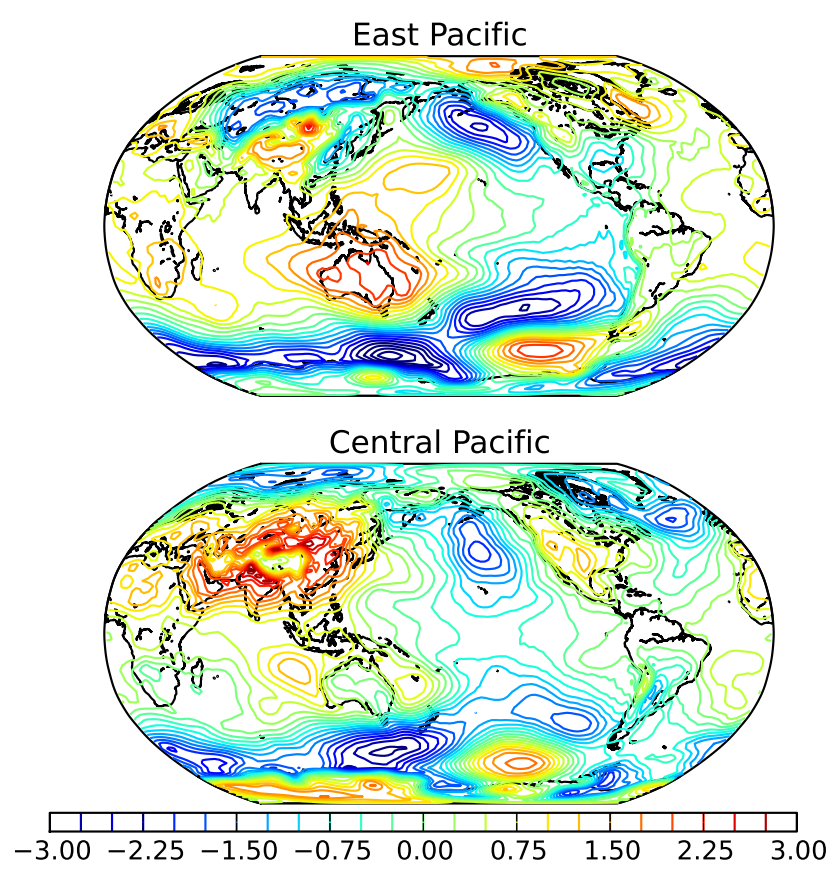

Figure 2. Difference in surface pressure anomaly between positive and negative phase of $N_{E P}$ and $N_{C P}$, as defined in equation(11). 

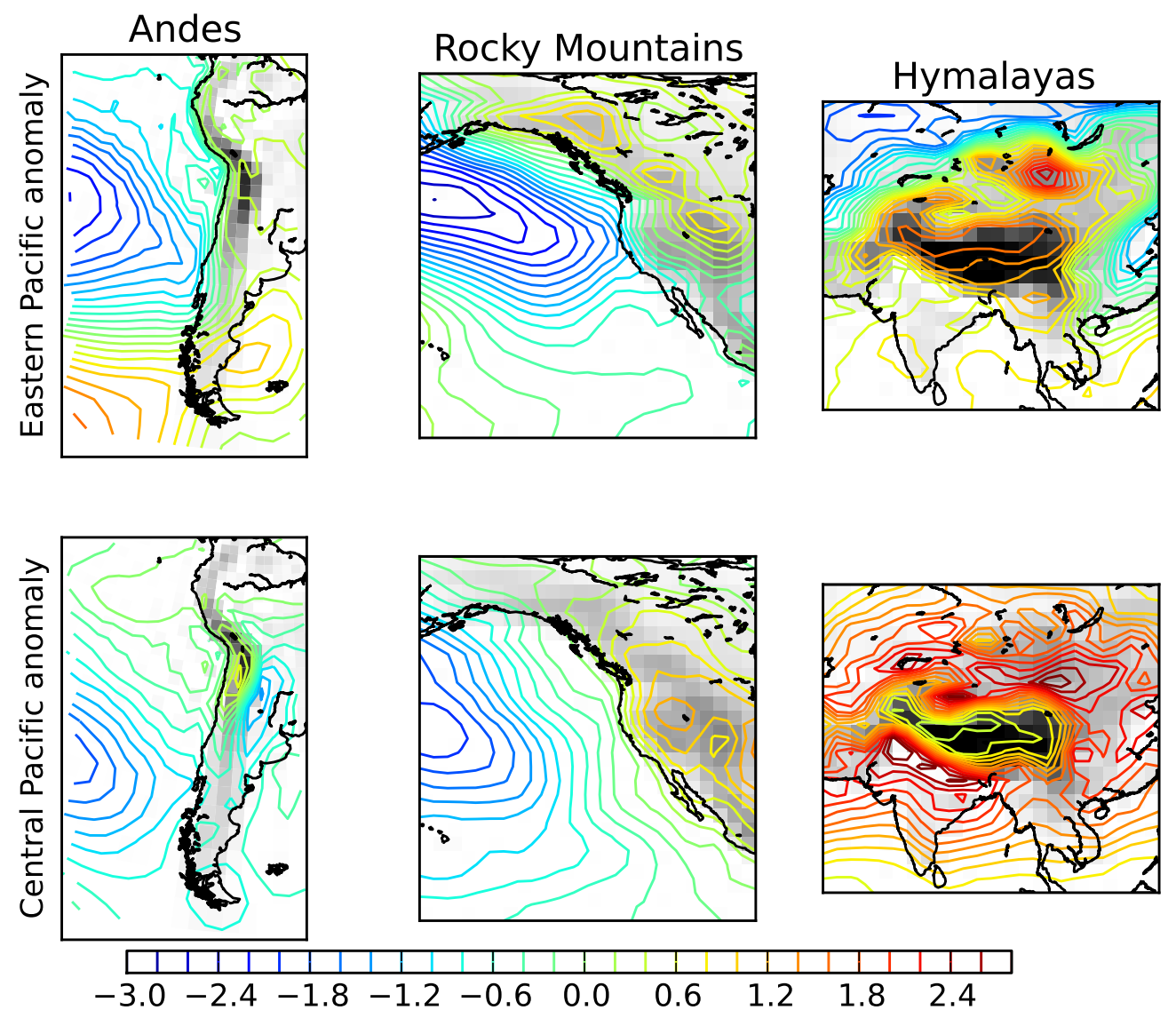

Figure 3. Difference in surface pressure anomaly between positive and negative phase of $N_{E P}$ and $N_{C P}$, as defined in equation(11), focused on the major mountain ranges (Andes on the left, Rocky Mountains on the center, and Himalayas on the right). The top panel is for EP anomaly and the bottom one for the CP anomaly.

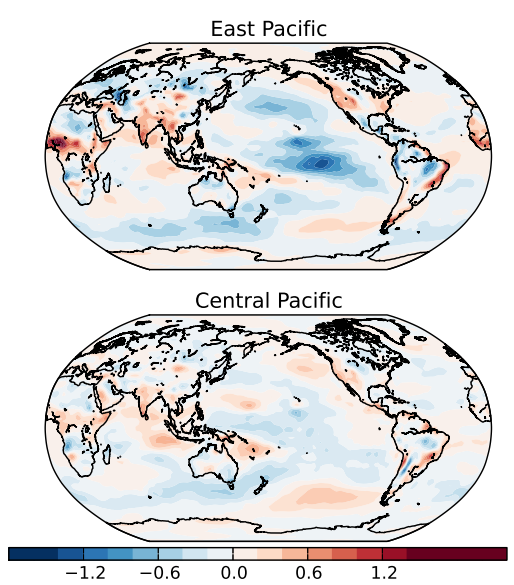

Figure 4. Difference in zonal friction drag anomaly between positive and negative phase of $N_{E P}$ and $N_{C P}$, as defined in equation(11). The top panels is for the EP anomaly and the bottom one for the CP anomaly. 
Table 1. Mountain torque (in Hadley, i.e. $10^{18} \mathrm{Nm}$ ), computed from $C_{E P}$ and $C_{C P}$ of the surface pressure, computed as explained by equation (11).

\begin{tabular}{lrr}
\hline Continent & East Pacific & Central Pacific \\
\hline Africa & 1.2 & 0.8 \\
Europe & -0.4 & 0.1 \\
N America & 1.7 & 1.0 \\
S America & 1.1 & 0.0 \\
Asia & 1.7 & 0.2 \\
Oceania & 0.2 & -0.1 \\
Antarctica & -0.1 & 0.1 \\
\hline Total & 5.4 & 2.1 \\
\hline
\end{tabular}

Table 2. Friction torque (in Hadley, i.e. $10^{18} \mathrm{Nm}$ ), computed from $C_{E P}$ and $C_{C P}$ of the friction drag, computed as explained by equation (11). The separation map for the ocean/continent can be found in Figure 3 of Marcus et al. [2011].

\begin{tabular}{lrr}
\hline Continent/ocean & East Pacific & Central Pacific \\
\hline Africa & 1.2 & 0.1 \\
Europe & -1.0 & -0.1 \\
N America & 0.5 & 0.1 \\
S America & 0.0 & 0.3 \\
Asia & 0.1 & -0.2 \\
Oceania & -0.2 & -0.2 \\
Antarctica & 0.5 & 0.2 \\
N Pac & -2.0 & 0.2 \\
Eq. Pac & -3.9 & -1.3 \\
S Pac & -1.7 & -0.3 \\
N Atl & -0.3 & -0.4 \\
Eq. Atl & 0.3 & 0.2 \\
S Atl & -1.4 & -0.9 \\
Indian & -2.0 & -1.1 \\
Antarctic Ocean & 0.1 & -0.0 \\
\hline Total & -9.9 & -3.3 \\
\hline
\end{tabular}

